\section{EARLY CLINICAL MANIFESTATIONS OF HUNTER SYNDROME - DATA FROM EUROPEAN PATIENTS IN THE HUNTER OUTCOME SURVEY}

\section{A. Tylki-Szymańska, HOS European Board} Instytut Pomnik-Centrum Zdrowia Dziecka, Warszawa, Poland

Background and aims: Hunter syndrome (mucopolysaccharidosis type II, MPS II) is an X-linked disorder of glycosaminoglycans (GAGs) catabolism caused by a deficient activity of the lysosomal enzyme, iduronate-2-sulfatase.

Methods: The Hunter Outcome Survey (HOS), a global database used to characterize the natural history of the disease as well as evaluate the safety and effectiveness of enzyme replacement therapy (ERT) with idursulfase Elaprase $^{\circledR}$, Shire HGT, Cambridge, MA, USA), was queried.

Results: As of 22 January 2010, a total of 57 untreated European patients were less than 10 years old at HOS entry. In this population, the median age at the onset of symptoms and the diagnosis of Hunter syndrome was 1.5 years $\left(10^{\text {th }}\right.$ to $90^{\text {th }}$ percentile: 0.3 to 2.5 years) and 2.5 years (1.3 to 5.4 years), respectively. In patients with available data the most common clinical manifestations were: coarse facial features (median age at onset 1.8 years, prevalence, 97.6\%), hepatosplenomegaly (2.2 years, $91.5 \%)$, chest and lung symptoms (1.8 years, $90.2 \%)$, enlarged tongue (2.0 years, $79.5 \%)$, enlarged tonsils/adenoids (2.8 years, $77.1 \%)$, joint stiffness (2.5 years, $76.7 \%$ ), hernia (1.3 years, $74.5 \%$ ), and recurrent otitis media (1.8 years, $65.9 \%)$. Neurological manifestations were reported by $95.7 \%$ of patients and included behaviour problems (3.6 years, 66.0\%), hyperactivity (3.0 years, $61.7 \%)$, cognitive problems (2.9 years, $61.7 \%$ ), and fine motor skills impairment (3.6 years, $48.9 \%)$.

Conclusions: These results indicate the early onset of the common clinical manifestations of Hunter syndrome. These data should increase awareness and help physicians identify and diagnose Hunter syndrome at an early age.
294

\section{DISRUPTION OF HIGHLY CONSERVED NON- CODING DNA ELEMENTS IN CONGENITAL HEART DEFECTS}

\author{
I.D. Krantz, L. Francey, J. Holst, L. Conlin, \\ N. Spinner, D. Juhr, P.J. Gruber \\ Children's Hospital of Philadephia, \\ Philadelphia, PA, USA
}

Background and aims: Congenital heart defects (CHDs) represent the most common structural birth defect in humans. While the identification of specific genes in these disorders have contributed to our understanding of cardiac development, they have not provided significant insight into the etiology of common, non-syndromic forms of CHDs. Our goal was to identify the copy number variants (CNVs) associated with CHDs.

Methods: We used a systematic approach using high-resolution SNP genotyping arrays to identify CNVs priority ranked based on their potential pathogenicity using a program, Perl Copy Numbers of Potential Interest (PECONPI), developed in our lab. PECONPI identifies disruptions in highly conserved non-coding regions $1 \mathrm{Mb}$ upstream or downstream to known developmental cardiac loci. We screened of 362 probands with CHDs and 3000 controls using PECONPI.

Results: We identified over 150 candidate CNVs that meet the criteria: 1) highly or ultra-conservation, 2) within $1 \mathrm{Mb}$ of a candidate locus, and 3) not present in control samples. We identified a cluster of overlapping deletions involving a conserved noncoding element (CNCE) on 2p13.3 in 7 unrelated probands, 6 with identical $5 \mathrm{~Kb}$ deletions and one with a smaller I Kb deletion, not seen in 3000 controls. This included 4 with TGA, 1 with TOF, 1 with a vascular ring, and 1 with unbalanced atrioventricular canal.

Conclusions: The presence of TGAs in 4/7 (57\%) is discordant from the total population screened in which TGAs were present in $46 / 362(13 \%)$ of the probands. Thus we have identified a novel CNCE for CHD. 